\title{
Efeito de Fatores Ambientais sobre a Seletividade do Alachlor AO Algodoeiro ${ }^{1}$
}

\author{
Effect of Environmental Factors on the Selectivity of Alachlor to Cotton
}

GUIMARÃES, S.C. ${ }^{2}$, HRYCYK, M.F. ${ }^{3}$ e MENDONÇA, E.A.F. ${ }^{4}$

\begin{abstract}
RESUMO - Cotonicultores do cerrado, receosos da ocorrência de fitotoxicidade, têm utilizado o herbicida alachlor em dosagens inferiores à mínima recomendada na bula, com baixo efeito residual. Com o objetivo de estudar fatores relacionados à seletividade do alachlor ao algodoeiro, foram realizados dois experimentos. No primeiro, em caixas de germinação com substrato areia, foi estudado o herbicida alachlor em dois niveis (sem alachlor e na dose de $96 \mu \mathrm{g} \mathrm{kg}^{-1}$ de substrato), em ambientes compostos pela combinação das temperaturas de $20,25,30$ e $35^{\circ} \mathrm{C}$ com três níveis de umidade no substrato $(40,60$ e $80 \%$ da capacidade de retenção de água). A avaliação foi realizada aos 10 dias. As condições do ambiente influenciaram o crescimento das plântulas, mas essa resposta foi reduzida ou anulada na presença do alachlor; quanto mais favoráveis as condições, proporcionalmente maiores foram as reduções. O herbicida reduziu características da parte aérea e, em maior intensidade, o comprimento das raizes. No segundo ensaio, em vasos com solo, foram estudados três tratamentos de irrigação $(23,34 \mathrm{e} 45 \mathrm{~mm})$ após aplicação de dois níveis de alachlor $(0$ e $\left.2,88 \mathrm{~kg} \mathrm{ha}^{-1}\right)$. A avaliação foi realizada aos 21 dias. Maiores níveis de irrigação causaram redução na matéria fresca e seca das raízes. O alachlor reduziu todas as variáveis medidas na parte aérea das plantas, mas, de modo geral, esse efeito foi de baixa intensidade e ocorreu de maneira semelhante nos níveis de irrigação. A independência dos efeitos entre alachlor e irrigação não corroboraram a premissa de que maiores niveis de água aumentariam a lixiviação do herbicida e a fitotoxicidade ao algodoeiro.
\end{abstract}

Palavras-chave: alachlor, algodão, fitotoxicidade, injúria.

\begin{abstract}
Brazilian savanna cotton growers in fear of phytotoxicity have been using the herbicide alachlor below the minimum dosage recommended by the manufacturer, with low residual activity. Two experiments were carried out to study factors related to alachlor selectivity to cotton. The firstassay use dgermination boxes with sand substrate to study two alachlorrates $\left(0\right.$ and $\left.96 \mu \mathrm{g} \mathrm{kg}^{-1}\right)$ at temperatures of $20,25,30$, and $35{ }^{\circ} \mathrm{C}$, combined with three levels of substrate moisture $(40 \%$, $60 \%$, and $80 \%$ of water holding capacity) and evaluated after 10 days. Seedling growth was affected by environmental conditions, but this response was reduced or cancelled when alachlor was present, with better conditions causing proportionally greater growth reductions. The herbicide caused reductions in aerial part traits and, to a greater extent, in root length. The second assay consisted of pots filled with soil substrate and three irrigation treatments $(23,34$, and $45 \mathrm{~mm})$ studied after application of two alachlor levels ( 0 and $2.88 \mathrm{~kg} \mathrm{ha}^{-1}$ ), and evaluated after 21 days. Higher irrigation levels caused reductions in fresh and dry matter of the roots. Alachlor reduced all variables measured in the aerial part of the cotton plants, but this effect, in general, had low intensity and was similar for all the irrigation levels. The independent effect between alachlor and irrigation does not support the assumption that higher water levels would increase herbicide leaching and its phytotoxicity to cotton.
\end{abstract}

Keywords: alachlor, cotton, phytotoxicity, injury.

Recebido para publicação em 29.4.2007 e na forma revisada em 29.11.2007.

2 Professor FAMEV/UFMT, Cuiabá, MT (sheep@ufmt.br); ${ }^{3}$ Professora UNEMAT, Alta Floresta, MT; ${ }^{4}$ Professora FAMEV/ UFMT, Cuiabá, MT. 


\section{INTRODUÇÃO}

O Brasil está entre os sete países que mais produzem algodão, com área plantada de $1.179,4$ mil ha e produtividade de $2.906 \mathrm{~kg} \mathrm{ha}^{-1}$ (CONAB, 2006). A região Centro-Oeste responde por $65 \%$ dessa produção, e o Estado de Mato Grosso, nesse periodo, plantou 438,4 mil ha, com produtividade de $3.420 \mathrm{~kg} \mathrm{ha}^{-1}$ (CONAB, 2006). A maior parte da área cultivada com algodoeiro em Mato Grosso é constituída por lavouras de grande extensão, geridas por empresas agricolas, com alto uso de insumos e custo de produção elevado.

Um dos problemas enfrentados pelos cotonicultores refere-se às plantas daninhas, que precisam ser controladas devido à competição com a cultura por nutrientes, água, luz e espaço (Melhorança \& Beltrão, 2001) e, também, em razão dos efeitos alelopáticos e prejuízos que podem causar às fibras durante a colheita e/ou beneficiamento (Beltrão, 2004). A convivência da lavoura com plantas daninhas pode acarretar perdas de mais $90 \%$ no rendimento de fibra, sendo necessário, para o rendimento máximo, que a cultura seja mantida livre das espécies daninhas durante o período crítico de prevenção da interferência, bem como no final do ciclo, para garantir a qualidade das fibras (Beltrão, 2004).

$\mathrm{Na}$ cultura do algodoeiro, o período crítico de interferência ocorre entre 15 e 60 dias após a emergência (Pitelli, 1985; Deuber, 1999; Melhorança \& Beltrão, 2001); em condições irrigadas, ele varia da emergência até 60 a 80 dias, de acordo com o ciclo do cultivar (Embrapa, 2003).

Dentre as práticas de manejo de plantas daninhas, o controle químico tem sido o mais utilizado em grandes áreas de plantio, principalmente por ser um método rápido e eficiente. Entretanto, as opções de herbicidas seletivos para a cultura do algodoeiro são limitadas, o que leva os cotonicultores a utilizar produtos com seletividade marginal, com risco de causar danos à cultura, ou obter controle deficiente das plantas daninhas pelo uso de subdoses.

O manejo das plantas daninhas no algodoal inclui, além das aplicações dos dessecantes, o uso de herbicidas seletivos em pré e em pós-emergência, bem como de outros herbicidas em pós-emer gência dirigida (Takizawa, 2004). Os herbicidas de pré-emergência são utilizados isolados ou em mistura e, geralmente, complementados pelas práticas de controle em pós-emergência (mecânicas e/ ou químicas). O alachlor é uma das opções de uso em pré-emergência, a qual consiste na utilização do produto após a semeadura, porém antes da germinação das sementes das plantas daninhas e do algodoeiro (Azevedo et al., 1999). Esse herbicida está registrado no Brasil para uso em várias culturas, com controle sobre gramineas e algumas dicotiledôneas, como a trapoeraba, mas sua eficiência no algodoeiro tem sido reduzida devido ao uso de doses abaixo das registradas, pelo risco de toxicidade que apresenta para essa cultura.

A questão da toxicidade à cultura é um problema constantemente relacionado aos herbicidas aplicados em pré-emergência, já que são poucos os produtos totalmente seletivos ao algodoeiro (Takizawa, 2004). O alachlor é tido como alternativa econômica para controle de algumas plantas daninhas no algodoeiro, visto que os herbicidas de pós-emergência totalmente seletivos têm preços elevados.

A dose de bula do alachlor varia de 2,4 a $3,6 \mathrm{~kg} \mathrm{ha}^{-1}$ (Rodrigues \& Almeida, 2005), enquanto a dose média usada pelos cotonicultores é de 1,68 $\mathrm{kg} \mathrm{ha}^{-1}$ ( Siqueri, 2006).

Como a seletividade de um tratamento herbicida decorre de complexa interação entre o herbicida, a planta e o ambiente (Klingman \& Ashton, 1975), o conhecimento dos fatores que regulam essa seletividade pode melhorar a eficiência no uso dessas substâncias, tanto no controle das plantas daninhas quanto na segurança para as culturas.

Este trabalho teve por objetivo estudar o efeito de fatores do ambiente sobre a seletividade do alachlor ao algodoeiro.

\section{MATERIAL E MÉTODOS}

Os experimentos foram instalados no Laboratório de Sementes e no Viveiro Experimental da Faculdade de Agronomia e Medicina Veterinária da Universidade Federal de Mato Grosso, em Cuiabá, no período de maio a outubro de 2005 . 
As sementes de algodoeiro, da variedade ITA-90, foram colhidas em junho de 2004 e armazenadas em câmara refrigerada até o uso $\left(17,0 \pm 1,5^{\circ} \mathrm{C}\right.$ de temperatura e $73 \pm 4 \%$ de umidade relativa do ar).

O substrato de solo usado proveio de área originalmente sob vegetação de cerrado, com os seguintes atributos: $634 \mathrm{~g} \mathrm{~kg}^{-1}$ de argila; $46,8 \mathrm{~g} \mathrm{dm}^{-3}$ de matéria orgânica; $117 \mathrm{~g} \mathrm{~kg}^{-1} \mathrm{de}$ silte; $249 \mathrm{~g} \mathrm{~kg}^{-1}$ de areia; $\mathrm{pH}$ (água $2: 1$ ) $=5,8$; $\mathrm{P}=8,6 \mathrm{mg} \mathrm{dm}^{-3} ; \mathrm{K}=104 \mathrm{mg} \mathrm{dm}^{-3} ; \mathrm{Ca}+\mathrm{Mg}=$ $5,7 \mathrm{cmol}_{\mathrm{c}} \mathrm{dm}^{-3} ; \mathrm{H}+\mathrm{Al}=7,2 \mathrm{cmol}_{\mathrm{c}} \mathrm{dm}^{-3}$; e capacidade de troca catiônica $=13,2 \mathrm{cmol}_{\mathrm{c}} \mathrm{dm}^{-3}$. Antes do uso o material foi destorroado, peneirado em malha de $3 \mathrm{~mm}$ e homogeneizado.

A determinação da capacidade de retenção de água do substrato, sempre que necessária, foi realizada seguindo as recomendações de Brasil (1992).

\section{Crescimento de plântulas do algodoeiro em função do herbicida alachlor e da temperatura e umidade do substrato}

O ensaio foi conduzido em laboratório com três niveis de umidade no substrato e quatro temperaturas.

O delineamento experimental foi inteiramente casualizado, com quatro repetições, e os tratamentos compostos por um fatorial $4 \times 3 \times 2$, sendo quatro temperaturas: 20,25 , 30 e $35^{\circ} \mathrm{C}$; três niveis de umidade do substrato: 40,60 e $80 \%$ da capacidade de retenção de água; e dois níveis do herbicida alachlor: 0 e $96 \mu \mathrm{gg}^{-1}$ de substrato. A dose de alachlor foi determinada em ensaios preliminares, realizados em areia umedecida a $60 \%$ de sua capacidade de retenção de água e à temperatura de $25^{\circ} \mathrm{C}$, testando-se várias concentrações do herbicida sobre o crescimento de plântulas do algodoeiro; foi selecionada a dose que causou redução de cerca de $50 \%$ no crescimento da maior raiz secundária. A unidade experimental foi uma caixa plástica com dimensões de $11 \times 11 \times 3 \mathrm{~cm}$ ("caixa gerbox"), tendo como substrato areia lavada, esterilizada a $100{ }^{\circ} \mathrm{C}$ por 24 horas.

Cada uma das caixas recebeu $0,4 \mathrm{~kg}$ de substrato, umedecido com água ou solução de alachlor, em quantidade suficiente para atingir 40, 60 ou $80 \%$ de sua capacidade de retenção. O substrato para as quatro repetições de cada tratamento foi preparado de uma só vez $(1,6 \mathrm{~kg})$, colocando-se a areia em camada de cerca de $1 \mathrm{~cm}$ sobre bandeja de aço inoxidável, sobre a qual se distribuiu a água ou solução de alachlor, promovendo-se em seguida, manualmente, a homogeneização do material.

Foram semeadas quatro sementes da variedade ITA-90 em cada caixa, que foram tampadas, envoltas em filme plástico transparente e acondicionadas em câmaras de germinação tipo BOD, com fotoperíodo de oito horas, reguladas para as temperaturas desejadas.

Aos dez dias realizou-se a avaliação das plântulas, medindo-se as variáveis: altura de planta, obtida a partir do colo até a inserção da gema apical, comprimento da raiz principal e comprimento da maior raiz secundária, obtidos por meio de régua plástica graduada com precisão de $1 \mathrm{~mm}$. Em seguida, o sistema radicular foi separado da parte aérea por meio de corte na região do colo, com o auxílio de bisturi, e transferido dentro de sacos de papel para estufa a $80^{\circ} \mathrm{C}$ por 24 horas, para obtenção da matéria seca. As pesagens foram realizadas em balança eletrônica com precisão de 0,0001 g.

Os dados foram submetidos à análise de variância, apresentando-se graficamente as interações alachlor $\mathrm{x}$ temperatura e alachlor $\mathrm{x}$ umidade, juntamente com o modelo de regressão ajustado, quando pertinente. As análises foram realizadas no programa SISVAR, e o nível de significância adotado foi de $\mathrm{p}=0,10$.

\section{Crescimento inicial do algodoeiro em função do herbicida alachlor e de três niveis de irrigação após sua aplicação}

O experimento foi realizado em viveiro, no delineamento experimental inteiramente casualizado, com quatro repetições, sendo cada unidade experimental representada por um vaso plástico, com $2 \mathrm{~kg}$ de substrato de solo, que receberam quatro sementes na profundidade de $1 \mathrm{~cm}$. Os tratamentos foram compostos por fatorial $3 \times 2$, formados por três niveis de irrigação: lâminas d'água de 23, 34 e $45 \mathrm{~mm}$, correspondentes a 400, 600 e $800 \mathrm{~mL}$ por vaso; e dois niveis do herbicida: sem alachlor e com alachlor, aplicado na dose de $2,88 \mathrm{~kg} \mathrm{ha}^{-1}$. 
O substrato foi inicialmente umedecido para atingir a capacidade de retenção de $60 \%$ e reumedecido sempre que necessário.

O herbicida foi aplicado imediatamente após a semeadura, por meio de um pulverizador costal pressurizado a gás carbônico, mantido a pressão constante de $300 \mathrm{kPa}$, portando barra com um bico de ponta de jato plano 110.03, com gasto de calda de $310 \mathrm{~L} \mathrm{ha}^{-1}$. Durante a aplicação, a altura do bico ao alvo foi de aproximadamente $40 \mathrm{~cm}$, a temperatura do ambiente era de $37^{\circ} \mathrm{C}$ e não havia ventos. Em seguida, irrigou-se o substrato até atingir nivel estabelecido para cada tratamento. Essa operação foi em etapas, colocando-se, de cada vez, cerca de $50 \mathrm{~mL}$ em cada vaso e esperando que ocorresse a infiltração de todo o conteúdo antes de novas adições, até completar a quantidade estabelecida para cada tratamento. Subseqüentemente, procurou-se repor a umidade do substrato sempre que os $5 \mathrm{~mm}$ superficiais se encontrassem secos, na quantidade suficiente para promover, visualmente, esse reumede cimento.

A avaliação foi realizada aos 21 dias após a semeadura, medindo-se a altura de planta do colo até a inserção da gema apical; a área da maior folha, estimada pela equação proposta por Medeiros (2006); o diâmetro do caule a $5 \mathrm{~cm}$ do solo; e a matéria fresca e seca da parte aérea e raízes. A altura foi medida com régua plástica graduada com precisão de $1 \mathrm{~mm}$, e o diâmetro, com paquímetro eletrônico com precisão de $0,02 \mathrm{~mm}$. Para obtenção da matéria fresca da parte aérea e das raízes, as plantas foram cortadas rente ao solo, acondicionadas em sacos de plástico transparente e imediatamente pesadas em balança com precisão de 0,0001 g. As raízes foram separadas manualmente sobre peneira com malha de $3 \mathrm{~mm}$, adotando o mesmo procedimento descrito para a parte aérea. Em seguida, o material foi acondicionado em saco de papel e seco em estufa de circulação de ar a $80^{\circ} \mathrm{C}$ por 48 horas, findo o qual tiveram a massa determinada na mesma balança anteriormente referida.

Os dados foram submetidos à análise de variância, segundo o modelo fatorial, e, quando pertinente, as médias foram comparadas pelo teste de Scott e Knott com significância de $p=0,10$. Essas análises foram realizadas como auxílio do programa SISVAR.

\section{RESULTADOS E DISCUSSÃO}

\section{Crescimento de plântulas do algodoeiro em função do herbicida alachlor e da temperatura e umidade do substrato}

O alachlor interferiu nas características estudadas, sendo o seu efeito dependente da temperatura e da umidade do substrato, à exceção da matéria seca de raiz, para a qual não houve interação entre alachlor e umidade.

$\mathrm{Na}$ ausência de alachlor, as maiores alturas da parte aérea ocorreram nas temperaturas entre 25 e $30^{\circ} \mathrm{C}$ e no maior nivel de umidade, correspondente a $80 \%$ da capacidade de retenção de água (Figura 1). A presença de alachlor no substrato, em média, reduziu a altura das plântulas, promovendo atenuação da resposta dessa variável à temperatura e eliminação desta no caso da umidade (Figura 1). Como conseqüência, as maiores reduções relativas ocorreram nas condições que favoreceram o crescimento das plântulas. Nas condições em que houve maior restrição ao crescimento, como no nivel mais baixo de temperatura ou de umidade, não ocorreu efeito do alachlor.

O comprimento das raízes foi prejudicado pelo alachlor, com redução média de $46,9 \%$ para raiz principal e $34,6 \%$ para a maior raiz secundária, em relação ao tratamento sem o produto. Em ambiente sem alachlor, temperaturas entre 25 e $30^{\circ} \mathrm{C}$ proporcionaram maiores comprimentos de raiz (Figuras 2 e 3 ) e maior acúmulo de matéria seca de raiz (Figura 4). Quando se aplicou o herbicida, as respostas dessas características à temperatura foram anuladas ou reduzidas. $\mathrm{O}$ aumento da umidade causou discreta redução no comprimento das raizes, porém esse efeito não foi verificado quando se aplicou alachlor, em razão da redução imposta pelo herbicida ao crescimento desses órgãos. O nivel de umidade não modificou a resposta da matéria seca das raízes às combinações dos fatores alachlor e temperatura.

Diferentemente do preconizado para outras espécies, em algodoeiro o alachlor é citado como inibidor do sistema radicular (Liebl \& Ross, 2000), fato confirmado nesta pesquisa, que identificou o comprimento desse órgão como a variável mais sensivel. O mecanismo primário de ação mais aceito para as acetanilidas 

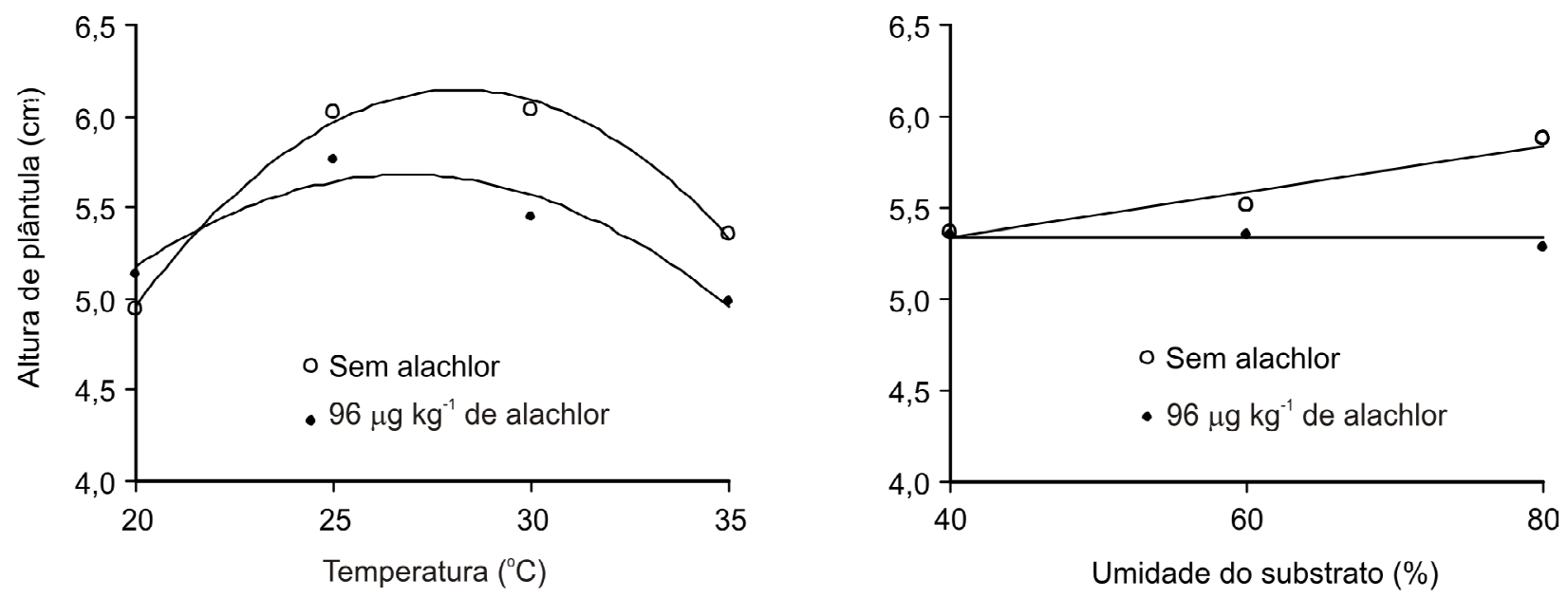

Figura 1 - Altura média das plântulas de algodoeiro, em função da aplicação de alachlor e da temperatura ou umidade de incubação. Os pontos são as médias dos valores observados, e as linhas, os valores preditos. Modelos para temperatura: sem alachlor $\hat{y}=-0,0176 x^{2}+0,9944 x-7,87 ; R^{2}=0,99 ;$ alachlor a $96 \mu g \mathrm{~kg}^{1} \hat{y}=-0,0109 x^{2}+0,5830 x-2,14 ; R^{2}=0,92$. Modelos para umidade: sem alachlor $\hat{y}=0,0127 \mathrm{x}+4,83 ; \mathrm{R}^{2}=0,95$; alachlor a $96 \mu \mathrm{g} \mathrm{kg}^{-1} \hat{\mathrm{y}}=5,33$.
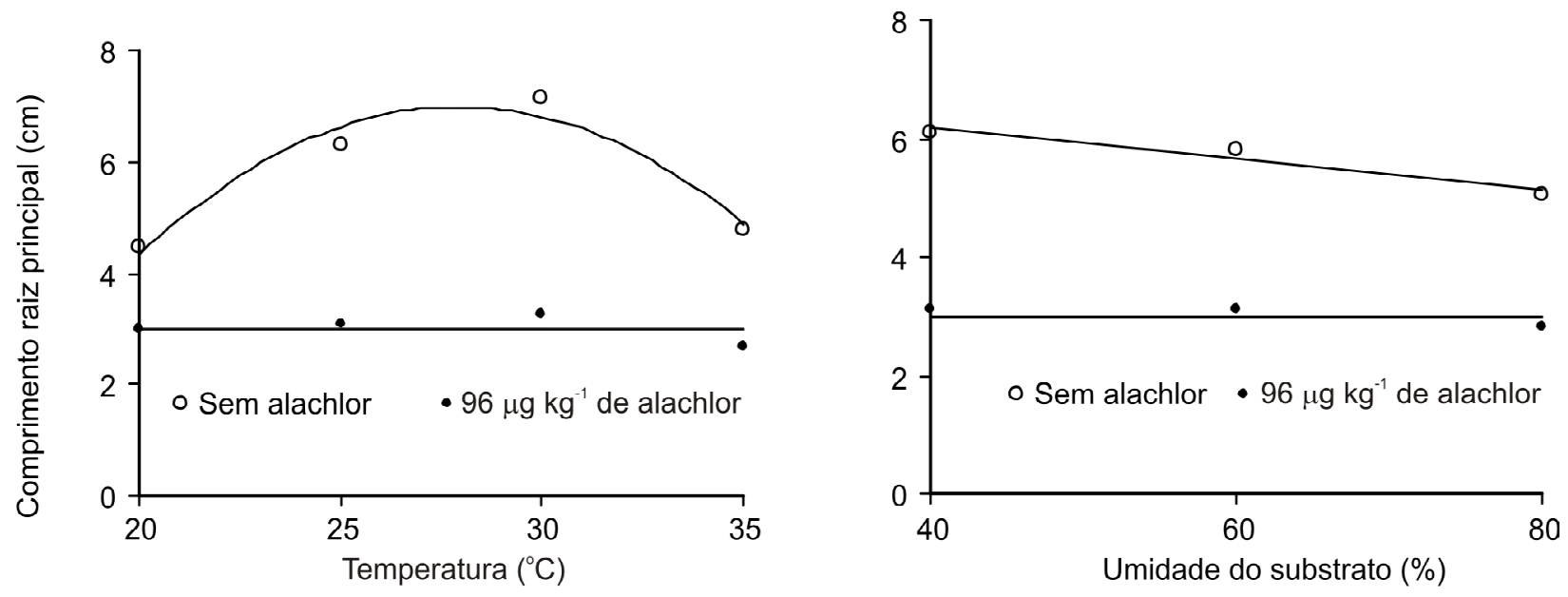

Figura 2 - Comprimento da raiz principal de plântulas de algodoeiro, em função da aplicação de alachlor e da temperatura ou umidade de incubação. Os pontos são as médias dos valores observados, e as linhas, os valores preditos. Modelos para temperatura: sem alachlor $\hat{y}=-0,0422 \mathrm{x}^{2}+2,3576 \mathrm{x}-25,93 ; \mathrm{R}^{2}=0,95$; alachlor a $96 \mu \mathrm{g} \mathrm{kg} \mathrm{y}^{-1} \hat{\mathrm{y}}=3,01$. Modelos para umidade: sem alachlor $\hat{y}=-0,0258 x+7,21 ; R^{2}=0,93$; alachlor a $96 \mu g \operatorname{kg} 1 \hat{y}=3,01$.

é a inibição da sintese dos ácidos graxos de cadeias muito longas (Silva et al., 2007). Entretanto, ainda não está esclarecida a ligação entre esse bloqueio e as alterações no crescimento de parte aérea e raízes de plântulas em desenvolvimento. Acredita-se que a inibição na sintese de proteinas seja um passo intermediário relevante no modo de ação (Silva et al., 2007), com as conseqüentes alterações nos processos de divisão e elongação celular.

Como o experimento foi realizado em areia lavada, houve grande disponibilidade do herbicida para absorção pelas sementes e plântulas, além do fato de que todo o sistema radicular ficou confinado à área tratada com o herbicida. Ressalta-se que esse produto não é recomendado para aplicação em solos arenosos (Rodrigues \& Almeida, 2005), devido aos riscos de fitotoxicidade, uma vez que a maior parte de sua sorção está relacionada à fração orgânica do solo (Vidal, 2002).

O maior efeito desse herbicida nas condições do ambiente consideradas ótimas ao desenvolvimento do algodoeiro poderia significar que, em campo, onde o algodoeiro é cultivado para expressar o máximo de sua produtividade, 

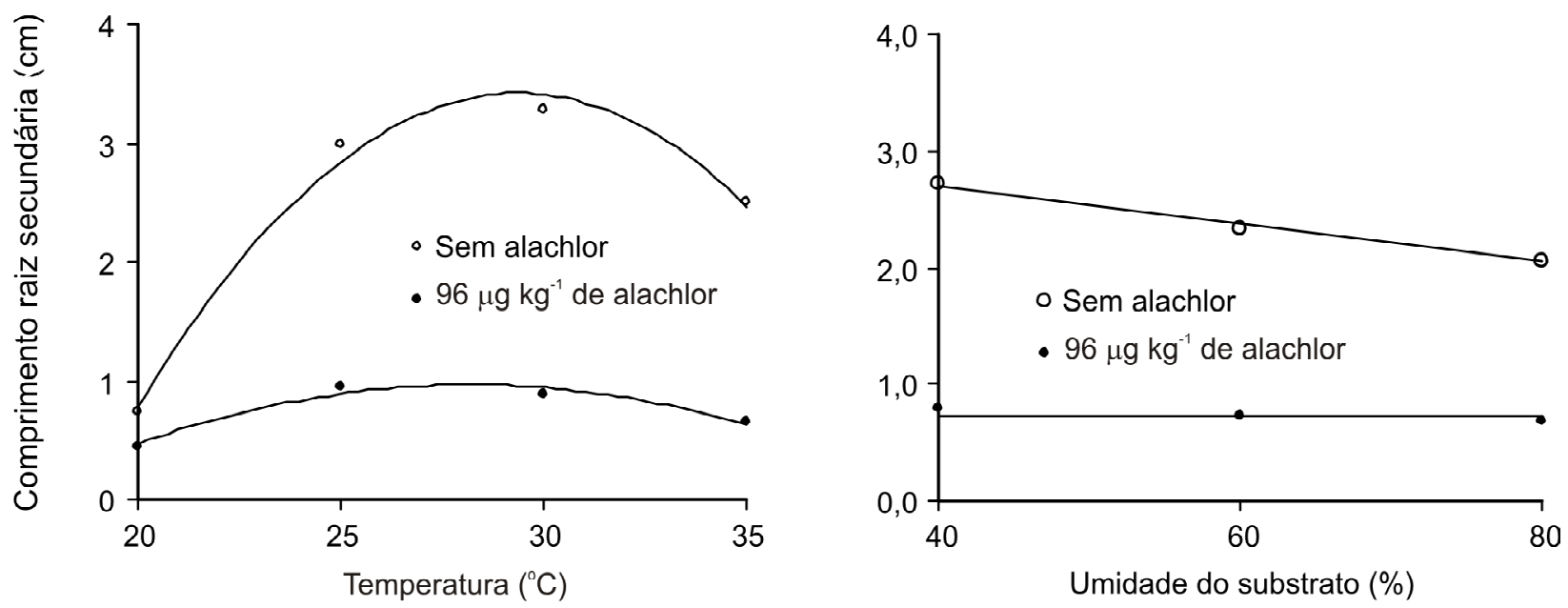

Figura 3 - Comprimento da maior raiz secundária de plântulas de algodoeiro, avaliado aos 10 dias, em função da aplicação de alachlor e da temperatura ou umidade de incubação. Os pontos são as médias dos valores observados, e as linhas, os valores preditos. Modelos para temperatura: sem alachlor $\hat{y}=-0,0302 \mathrm{x}^{2}+1,7725 \mathrm{x}-22,6 ; \mathrm{R}^{2}=0,99$; alachlor a $96 \mu \mathrm{gg} \mathrm{kg}^{-1} \hat{\mathrm{y}}=-0,0074$ $\mathrm{x}^{2}+0,4167 \mathrm{x}-4,91 ; \mathrm{R}^{2}=0,95$. Modelos para umidade: sem alachlor $\hat{y}=-0,0165 \mathrm{x}+3,36 ; \mathrm{R}^{2}=0,99$; alachlor a $96 \mu \mathrm{gg} \mathrm{kg}^{-1}$ $\hat{\mathrm{y}}=0,73$.
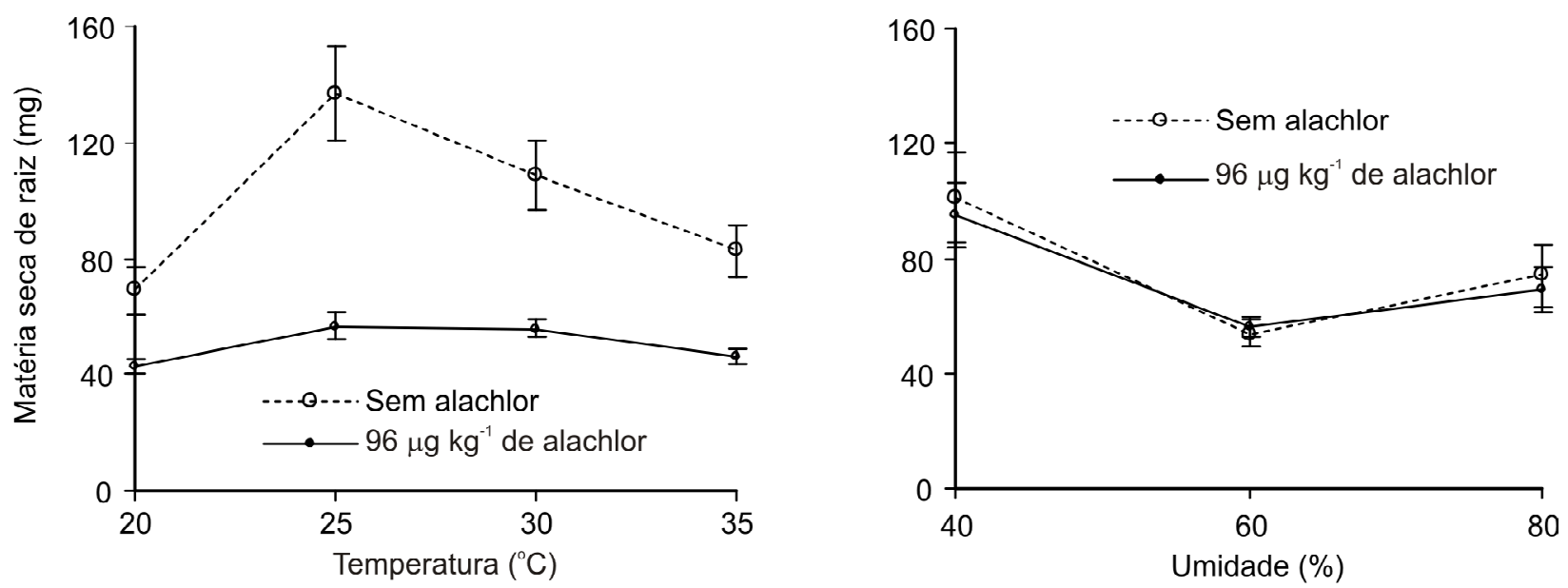

Figura 4 - Matéria seca de raízes de plântulas de algodoeiro, em função da aplicação de alachlor e da temperatura ou umidade de incubação. Os pontos são as médias dos valores observados e as barras representam \pm um erro-padrão da média.

os efeitos fitotóxicos do alachlor poderiam ser mais drásticos. No entanto, há que considerar que, quanto mais rápida for a emergência da plântula e o crescimento de suas raízes, menos tempo esses órgãos ficarão em contato com o herbicida e menor deve ser sua absorção. Corrobora essa assertiva a maior fitotoxicidade observada com alachlor em condições desfavoráveis à germinação, como baixa temperatura e alta umidade (Belote \& Monaco,1977; Putnam \& Rice Junior, 1979). Nesta pesquisa, a semeadura superficial propiciou rápida emergência das plântulas e, conseqüentemente, curto período de contato entre as estruturas da parte aérea (hipocótilo, cotilédones e epicótilo) e o substrato contendo o herbicida.

\section{Crescimento inicial do algodoeiro em fun- ção do herbicida alachlor e de três niveis de irrigação após sua aplicação}

A presença de alachlor reduziu todas as variáveis medidas na parte aérea das plantas do algodoeiro (Tabela 1), mas não teve efeito 
Tabela 1 - Altura de planta (AP), área da maior folha (AF), diâmetro do caule (DC), matéria fresca da parte aérea (MFA), matéria seca da parte aérea (MSA) e relação MFA/MSA em plantas de algodoeiro, em função da aplicação do herbicida alachlor

\begin{tabular}{|l|c|c|c|c|c|c|}
\hline \multicolumn{1}{|c|}{ Tratamento } & $\begin{array}{c}\mathrm{AP} \\
(\mathrm{cm})\end{array}$ & $\begin{array}{c}\mathrm{AF} \\
\left(\mathrm{cm}^{2}\right)\end{array}$ & DC $(\mathrm{cm})$ & $\begin{array}{c}\text { MFA } \\
(\mathrm{g} \text { por vaso) }\end{array}$ & $\begin{array}{c}\text { MAS } \\
(\mathrm{g} \text { por vaso })\end{array}$ & MFA/MSA \\
\hline Sem alachlor & $8,56 \mathrm{~A}^{*}$ & $9,47 \mathrm{~A}$ & $1,67 \mathrm{~A}$ & $7,30 \mathrm{~A}$ & $1,10 \mathrm{~A}$ & $6,69 \mathrm{~B}$ \\
\hline $\begin{array}{l}\text { Com alachlor } \\
\left(2,88 \mathrm{~kg} \mathrm{ha}^{-1}\right)\end{array}$ & $7,00 \mathrm{~B}$ & $8,24 \mathrm{~B}$ & $1,59 \mathrm{~B}$ & $6,76 \mathrm{~B}$ & $0,90 \mathrm{~B}$ & $7,62 \mathrm{~A}$ \\
\hline
\end{tabular}

* Médias nas colunas, seguidas de mesma letra, não diferem pelo teste de Scott \& Knott $(\mathrm{p}>0,10)$.

sobre aquelas tomadas nas raizes (Tabela 2). A irrigação, por sua vez, influenciou somente a matéria fresca e seca das raizes e a relação entre a matéria fresca da parte aérea e a das raízes (Tabelas 3 e 4). Não houve interação entre os fatores alachlor e niveis de irrigação para nenhuma das variáveis avaliadas $(p>0,10)$, indicando que a ação do alachlor foi independente da irrigação.

Em termos quantitativos, a presença do herbicida alachlor, em relação à testemunha, reduziu a altura das plantas em 18,1\%; a área foliar, em 12,9\%; o diâmetro do caule, em 4,8\%; e a matéria fresca da parte aérea (MFA), em $7,4 \%$. A redução na matéria seca da parte aérea (MSA), de $18,2 \%$, foi proporcionalmente maior que a observada na MFA, o que fez com que a relação MFA/MSA fosse maior na presença do herbicida. Esse resultado é coerente, uma vez que as alterações promovidas pelo alachlor, ao reduzir a parte aérea e não alterar as raízes (relação mais estreita em parte aérea e raízes), favorecem a ocorrência de maior turgidez na parte aérea.

É importante salientar que não foram observados os sintomas típicos de fitointoxicação freqüentemente relacionados ao herbicida alachlor, como as alterações na forma e cor das folhas, citadas por Putnam \& Rice Junior. (1979). Sintomas visuais de fitotoxicidade das acetanilidas nem sempre são visualizados, como no caso do uso de s-metolachlor em plantas

Tabela 2 - Matéria fresca da raiz (MFR), matéria seca da raiz (MSR), relação matéria fresca e seca da raiz (MFR/MSR) e relações entre a parte aérea e a raiz com base nas matérias frescas (MFA/MFR) e secas (MSA/MSR) em plantas de algodoeiro, em função da aplicação do herbicida alachlor

\begin{tabular}{|l|c|c|c|c|c|}
\hline \multicolumn{1}{|c|}{ Tratamento } & $\begin{array}{c}\text { MFR } \\
\text { (g por vaso) }\end{array}$ & $\begin{array}{c}\text { MSR } \\
\text { (g por vaso) }\end{array}$ & MFR/MSR & MFA/MFR & MSA/MSR \\
\hline Sem alachlor & $6,40 \mathrm{~A}^{*}$ & $0,69 \mathrm{~A}$ & $9,60 \mathrm{~A}$ & $1,15 \mathrm{~A}$ & $1,64 \mathrm{~A}$ \\
\hline $\begin{array}{l}\text { Com alachlor } \\
\left(2,88 \mathrm{~kg} \mathrm{ha}^{-1}\right)\end{array}$ & $6,69 \mathrm{~A}$ & $0,68 \mathrm{~A}$ & $10,06 \mathrm{~A}$ & $1,03 \mathrm{~B}$ & $1,37 \mathrm{~B}$ \\
\hline
\end{tabular}

* Médias nas colunas, seguidas de mesma letra, não diferem pelo teste de Scott \& Knott $(\mathrm{p}>0,10)$.

Tabela 3 - Altura de planta (AP), área da maior folha (AF), diâmetro do caule (DC), matéria fresca da parte aérea (MFA), matéria seca da parte aérea (MSA) e relação MFA/MSA em plantas de algodoeiro, em função da aplicação de três níveis de irrigação após aplicação do herbicida alachlor

\begin{tabular}{|c|c|c|c|c|c|c|}
\hline $\begin{array}{c}\text { Níveis de irrigação } \\
(\mathrm{mm})\end{array}$ & $\begin{array}{c}\mathrm{AP} \\
(\mathrm{cm})\end{array}$ & $\begin{array}{c}\mathrm{AF} \\
\left(\mathrm{cm}^{2}\right)\end{array}$ & $\begin{array}{c}\mathrm{DC} \\
(\mathrm{cm})\end{array}$ & $\begin{array}{c}\text { MFA } \\
(\mathrm{g} \text { por vaso) }\end{array}$ & $\begin{array}{c}\text { MAS } \\
(\mathrm{g} \text { por vaso) }\end{array}$ & MFA/MSA \\
\hline 23 & $7,94 \mathrm{~A}^{*}$ & $8,92 \mathrm{~A}$ & $1,67 \mathrm{~A}$ & $7,33 \mathrm{~A}$ & $1,09 \mathrm{~A}$ & $6,84 \mathrm{~A}$ \\
\hline 34 & $7,75 \mathrm{~A}$ & $8,84 \mathrm{~A}$ & $1,63 \mathrm{~A}$ & $6,90 \mathrm{~A}$ & $0,96 \mathrm{~A}$ & $7,29 \mathrm{~A}$ \\
\hline 45 & $7,66 \mathrm{~A}$ & $8,80 \mathrm{~A}$ & $1,59 \mathrm{~A}$ & $6,85 \mathrm{~A}$ & $0,95 \mathrm{~A}$ & $7,33 \mathrm{~A}$ \\
\hline
\end{tabular}

* Médias nas colunas, seguidas de mesma letra, não diferem pelo teste de Scott \& Knott $(\mathrm{p}>0,10)$. 
Tabela 4 - Matéria fresca de raiz (MFR), matéria seca de raiz (MSR), relação MFR/MSR e relações entre a parte aérea e raiz com base nas matérias frescas (MFA/MFR) e secas (MSA/MSR) em plantas de algodoeiro, em função de três níveis de irrigação após aplicação do herbicida alachlor

\begin{tabular}{|c|c|c|c|c|c|}
\hline $\begin{array}{c}\text { Nível de } \\
\text { irrigação }(\mathrm{mm})\end{array}$ & $\begin{array}{c}\text { MFR } \\
\text { (g por vaso) }\end{array}$ & $\begin{array}{c}\text { MSR } \\
\text { (g por vaso) }\end{array}$ & MFR/MSR & MFA/MFR & MSA/MSR \\
\hline 23 & $7,44 \mathrm{~A}^{*}$ & $0,82 \mathrm{~A}$ & $9,45 \mathrm{~A}$ & $0,99 \mathrm{~B}$ & $1,38 \mathrm{~A}$ \\
\hline 34 & $5,90 \mathrm{~B}$ & $0,63 \mathrm{~B}$ & $9,72 \mathrm{~A}$ & $1,18 \mathrm{~A}$ & $1,58 \mathrm{~A}$ \\
\hline 45 & $6,23 \mathrm{~B}$ & $0,62 \mathrm{~B}$ & $10,31 \mathrm{~A}$ & $1,09 \mathrm{~A}$ & $1,58 \mathrm{~A}$ \\
\hline
\end{tabular}

* Médias nas colunas, seguidas de letra comum, não diferem pelo teste de $\operatorname{Scott~} \& \operatorname{Knott~}(\mathrm{p}>0,10)$.

de algodoeiro (Freitas et al., 2006) e alachlor em cupuaçuzeiro (Silva et al., 2003).

Como a dose de $2,88 \mathrm{~kg} \mathrm{ha}^{-1}$, aplicada no experimento, embora dentro da faixa de recomendação, é muito superior àquela adotada pelos cotonicultores, que está entre 1,44 e $1,92 \mathrm{~kg} \mathrm{ha}^{-1}$ (Siqueri, 2006), eram esperados efeitos fitotóxicos mais drásticos do alachlor sobre as plantas do algodoeiro. Surpreendente, também, foi a não-interferência desse produto sobre a massa de raízes, visto que esse órgão das plantas foi mais sensivel que a parte aérea no experimento realizado em substrato de areia. Pode ter contribuído para a não-manifestação das respostas esperadas a maior sorção do alachlor, que ocorre em solos com teores mais elevados de argila e matéria orgânica (Ferri et al., 2006), como o desta pesquisa (634 $\mathrm{g} \mathrm{kg}^{-1}$ de argila e 46,8 $\mathrm{g} \mathrm{dm}^{-3}$ de matéria orgânica), como também as condições de alta umidade e temperatura do substrato, as quais favorecem o desenvolvimento de microrganismos do solo, e estes, a degradação dos herbicidas acetanilidas (Beestman \& Deming, 1974).

Jordan \& Harvey (1978) relataram que a fitotoxicidade em ervilha causada por herbicidas do grupo das acetanilidas aumentou com a irrigação. Esse fato não foi comprovado com algodoeiro nesta pesquisa, pois o volume de água aplicado ao solo após aplicação do herbicida, bem como a possivel movimentação no perfil do solo, não interferiu na intensidade da ação fitotóxica do alachlor. O rápido crescimento do sistema radicular do algodoeiro (Souza \& Beltrão, 1999), aliado à limitação de espaço imposta pelo recipiente, provavelmente fez com que houvesse, muito precocemente, ampla distribuição de raízes em todo o volume do vaso. Esse fato pode ter anulado as possiveis respostas esperadas em razão do posicionamento diferencial do herbicida no perfil do solo.

O algodoeiro é conhecido por ser sensivel a baixos níveis de oxigênio e responde via raízes às alterações na composição do ar do solo (Beltrão \& Souza, 2001). O alongamento da raiz principal é paralisado dentro de dois a três minutos quando o oxigênio é removido do sistema e, quando tratada com $100 \%$ de nitrogênio, por um periodo de três a cinco horas, a raiz principal invariavelmente morre (Huck, 1970). Essa característica fisiológica pode estar relacionada ao efeito negativo observado nas raízes, quando se aumentou a quantidade de água aplicada ao solo. A falta de reflexo desse efeito sobre a parte aérea pode estar relacionada à época de avaliação, realizada em plantas ainda pequenas e com baixa demanda de recursos do solo, os quais poderiam estar sendo supridos normalmente à parte aérea pelo sistema radicular, mesmo proporcionalmente menor. Corroboram esses resultados aqueles obtidos por Souza et al. (2001), em que o estresse anoxítico, causado por 8 e 10 dias de encharcamento, reduziu a altura de planta do algodoeiro.

Em solos com baixa capacidade de sorção, o herbicida alachlor pode causar redução no crescimento do sistema radicular do algodoeiro. Por outro lado, em condições de alta sorção, as doses de alachlor podem ser superiores àquelas utilizadas pelos cotonicultores, o que deve ser confirmado em estudos de campo em diferentes situações.

\section{LITERATURA CITADA}

AZEVEDO, D. M. P. et al. Plantas daninhas. In: O agronegócio do algodão no Brasil . v. 2. Brasília: Embrapa, 1999. p. 555-585. 
BEESTMAN, G. B.; DEMING, J. M. Dissipation of acetanilide herbicides from soil. Agron. J., v. 66, n. 1, p. 308-311, 1974.

BELOTE, J, N.; MONACO, T. J. Factors involved in alachlor injury to the potato (Solanum tuberosum). Weed Sci., v. 25, n. 6, p. 482-486, 1977.

BELTRÃO, N. E. M.; SOUZA, J. G. Fisiologia e ecofisiologia do algodoeiro. In: Algodão: tecnologia de produção. Dourados: Embrapa Agropecuária Oeste; Embrapa Algodão, 2001. p. 54-75.

BELTRÃO, N. E. M. Manejo de plantas daninhas em algodão. In: VARGAS, L.; ROMAN, E. S. (Eds.) Manual de manejo e controle de plantas daninhas. Bento Gonçalves: Embrapa Uva e Vinho, 2004. p. 215-250.

BRASIL. Ministério da Agricultura e Reforma Agrária. Regras para análise de sementes. Brasília: SNAD/CLAV, 1992. $365 \mathrm{p}$.

COMPANHIA NACIONAL DE ABASTECIMENTO CONAB. ASSUNTO 2006. Disponível em: <http:// www.conab.gov.br>. Acesso em: 14 fev. 2006.

DEUBER, R. Manejo integrado de plantas infestantes na cultura do algodoeiro. In. CIA, E.; FREIRE, E. C.; SANTOS, W. J. (Eds.). Cultura do algodoeiro. Piracicaba: Potafos, 1999. p.101-119.

\section{EMPRESA BRASILEIRA DE PESQUISA}

AGROPECUÁRIA - EMBRAPA. Cultivo de algodão irrigado. Campina Grande: 2003. Disponível em: $<$ http:// sistemas deproducao. cnptia.embrapa.br/F ontes HTML/ Algodao/AlgodaoIrrigado/plantasdaninhas.htm $>$. Acesso em: 10 de julho de 2006 .

FERRI, M. V. W. et al. Sorção do herbicida alachlor em solos com diferentes conteúdos de argila e carbono orgânico. 2006. Disponível em: <http://www.ufsm.br/ppgcs/congressos/ LINKS\%20DO\%20CBCS\%202003/ CBCS2003\%20EM\%20PDF/30.pdf>. Acesso em: 13 de jun. de 2006.

FREITAS, R. S. et al. Manejo de plantas daninhas na cultura do algodoeiro com S-metolachlor e trifloxysulfuron-sodium em sistema de plantio convencional. Planta Daninha, v. 24, n. 2, p. 311-318, 2006.

HUCK, M. G. Variation in taproot elongation rate as influenced by composition of the soil air. Agron. J., v. 62, n. 6, p. $815-818,1970$.

JORDAN, G. L.; HARVEY, R. G. Response of processing peas (Pisum sativum) and annual weeds to acetanilide herbicides. Weed Sci., v. 26, n. 4, p. 313-317, 1978.

KLINGMAN, C. G.; ASHTON, F. M. Weed science: principles and practices. New York: John Wiley, 1975. 431 p.
LIEBL, R.; ROSS, M. A. Cell growth disrupters and inhibitors. In: Herbicide action course. West Lafayette: Purdue University, 2000. p. 244-267.

BRASIL - MINISTÉRIO DA AGRICULTURA, PECUÁRIA E ABASTECIMENTO - MAPA. ASSUNTO. 2006. Disponível em: $<$ http://www.agricultura.gov.br $>$. Acesso em: 11 de julho de 2006.

MELHORANÇA, A. L.; BELTRÃO, N. E. M. Plantas daninhas: importância e controle. In: EMPRESA BRASILEIRA DE PESQUIS A AGROPECUÁRIA EMBRAPA. Algodão: tecnologia de produção. Dourados: Embrapa Agropecuária Oeste; Embrapa Algodão, 2001. p. $227-237$.

PITELLI, R. A. Interferência de plantas daninhas em culturas agrícolas. Inf. Agropec., v. 11, n. 129, p. 16-27, 1985.

PUTNAM, A. R.; RICE JUNIOR, R. P. Environmental and edaphic influences on the selectivity of alachlor on snap beans (Phaseolus vulgaris). Weed Sci., v. 27, n. 5, p. 570574, 1979.

RODRIGUES, B. N.; ALMEIDA, F. S. Guia de herbicidas. 5.ed. Londrina: Edição dos Autores, 2005. p. 10-15.

SILVA, A. A.; FERREIRA, F. A.; FERREIRA, L. R. Herbicidas: classificação e mecanismo de ação. In: SILVA, A. A.; SILVA, J. F. (Eds.). Tópicos em manejo de plantas daninhas. Viçosa, MG: Universidade Federal de Viçosa, 2007. p. 83-148.

SILVA, J. F.; BUENO, C. R.; SOUZA, A. G. C. Eficácia de herbicidas no controle de plantas daninhas e seletividade em leguminosas de cobertura e cupuaçuzeiro. Planta Daninha, v. 21, n. 1, p. 137-143, 2003.

SIQUERI, F. V. Controle de ervas daninhas em préemergência. Fundação Mato Grosso, 2006. Disponível em: $<$ http://www.algodao.agr.br/cms/index.php >. Acesso em: 12 de julho de 2006.

SOUZA, J. G.; BELTRÃO, N. E. M. Fisiologia. In: O agronegócio do algodão no Brasil. Brasília: Embrapa, 1999. v. 1. p. 89-116.

SOUZA, J. G.; BELTRÃO, N. E. M.; SANTOS, J. W. Fisiologia e produtividade do algodoeiro em solo encharcado na fase de plântula. Pesq. Agropec. Bras., v. 36, n. 3, p. $425-430,2001$.

TAKIZAWA, E. K. Manejo de plantas invasoras na cultura do algodão. In: FÓRUM MATO-GROSSENSE DA CULTURA DO ALGODOEIRO, 1., 2004, Cuiabá. Anais... Cuiabá: Universidade Federal do Mato Grosso, 2004. p. 6170 .

VIDAL, R. Ação dos herbicidas: absorção, translocação e metabolização. Porto Alegre: Universidade Federal do Rio Grande do Sul, 2002. 89 p.

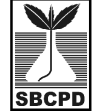

